Thin Films

\title{
Spray-On Organic/Inorganic Films: A General Method for the Formation of Functional Nano- to Microscale Coatings
}

\author{
Mathias Lefort, Gabriela Popa, Emek Seyrek, Rafael Szamocki, Olivier Felix, Joseph Hemmerlé, \\ Lö̈c Vidal, Jean-Claude Voegel, Fouzia Boulmedais, Gero Decher,* and Pierre Schaaf*
}

Surface coatings are important in science and technology with applications that span domains as diverse as biomaterials, optical coatings, photovoltaic cells, or corrosion protection. ${ }^{[1-4]}$ Such applications were enabled by the development of methods for the preparation of organic and inorganic thin films that either involve transfer through the gas phase (e.g., physical vapor deposition (PVD), chemical vapor deposition (CVD), sputtering $)^{[5,6]}$ or deposition from solution (e.g., solgel methods, spin-coating, electrospraying, spray pyrolysis, electroplating) ${ }^{[7-9]}$ Many methods are also specific for a given application and only a few are applicable to a wide range of materials and surfaces. A potent and simple solution-based method for the preparation of multicomposite nanoscale films on surfaces of almost any kind and any shape is the wellknown layer-by-layer (LbL) method. ${ }^{[10]}$ The introduction of spray-assisted deposition was an important improvement of the LbL technique with respect to accelerating and scaling up of the process. ${ }^{[1-14]}$

$[*]$ M. Lefort, ${ }^{[+]}$G. Popa, ${ }^{[+]}$Dr. E. Seyrek, Dr. R. Szamocki, Dr. O. Felix, Dr. F. Boulmedais, Prof. G. Decher, Prof. P. Schaaf

Institut Charles Sadron (UPR 22)

Centre National de la Recherche Scientifique

23 rue du Loess, 67034 Strasbourg (France)

Fax: (+33) 3-9041-4000

E-mail: gero.decher@ics-cnrs.unistra.fr pierre.schaaf@ics-cnrs.unistra.fr Homepage: http://www-ics.u-strasbg.fr

Dr. J. Hemmerlé, Dr. J.-C. Voegel

Biomaterials and Tissue Engineering (UMR 977), Institut National de la Santé et de la Recherche Médicale Strasbourg (France) and

Faculté de Chirurgie Dentaire, Université de Strasbourg (France)

Dr. L. Vidal

Institut de Science des Matériaux de Mulhouse (LRC 7228)

Centre National de la Recherche Scientifique, Mulhouse (France)

Prof. G. Decher

Faculté de Chimie, Université de Strasbourg

1 rue Blaise Pascal, 67008 Strasbourg (France)

and

International Center for Frontier Research in Chemistry

8 allée Gaspard Monge, 67083 Strasbourg (France)

and

Institut Universitaire de France

103 Boulevard Saint-Michel, 75005 Paris (France)

Prof. P. Schaaf

Ecole Européenne de Chimie, Polymères et Matériaux, Université de Strasbourg, 25 rue Becquerel, 67087 Strasbourg (France)

$\left[{ }^{+}\right]$These authors contributed equally to this work.

Supporting information for this article is available on the WWWW under http://dx.doi.org/10.1002/anie.201002729.
Herein we show that spray-assisted LbL deposition can be further advanced to lead to a general method, the so-called "simultaneous spray coating of interacting species" (SSCIS). Instead of bringing two spontaneously interacting species into contact step-by-step at an interface to form LbL films, SSCIS is based on the simultaneous spraying of two or more interacting components against a receiving surface. This process results in a fast reaction between the complementary components on a macroscopic surface, hence leading to a continuous and gradual buildup of a coating, the thickness of which is controlled by the spraying time, while the solvent and excess material are removed by drainage. This one-step deposition process is extremely user-friendly and allows the preparation of very homogeneous films, which show optical interference colors over large areas (Figure 1). This property is a prerequisite for the fabrication of, for example, optical devices. The uniform color of the films when exposed to white light indicates a homogeneous refractive index and thickness, which is of the order of a hundred nanometers with a variation of a few nanometers over the entire surface (excluding some edge effects). The film thickness can easily be tuned from a few tens up to hundreds of nanometers and even micrometers simply by varying the spraying time. The results and

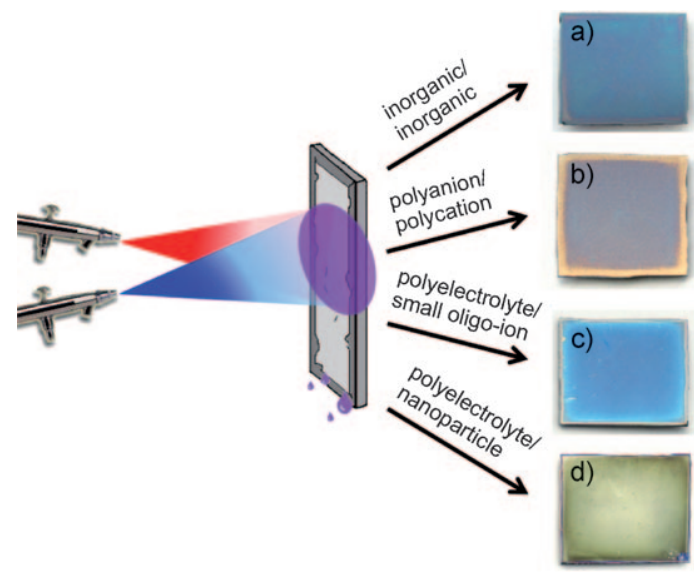

Figure 1. Left: Representation of the simultaneous spray coating (SSCIS) setup. Right: Images of films deposited on silicon wafers $(40 \mathrm{~mm} \times 40 \mathrm{~mm})$; the colors arise from optical interference. The sprayed solutions are: a) $\mathrm{NaF}\left(2 \times 10^{-2} \mathrm{~mol} \mathrm{~L}^{-1}\right)$ and $\mathrm{CaCl}_{2} \cdot 2 \mathrm{H}_{2} \mathrm{O}$ $\left(10^{-2} \mathrm{~mol} \mathrm{~L}^{-1}\right)$, b) PAH $\left(1 \mathrm{mg} \mathrm{mL}^{-1}, M_{\mathrm{n}}=15000 \mathrm{~g} \mathrm{~mol}^{-1}\right.$, in $0.6 \mathrm{~mol} \mathrm{~L}^{-1}$ aq $\mathrm{NaCl}$ ) and PSS $\left(1 \mathrm{mg} \mathrm{mL}^{-1}, M_{\mathrm{n}}=15000 \mathrm{~g} \mathrm{~mol}^{-1}\right.$, in $0.6 \mathrm{~mol} \mathrm{~L}^{-1}$ aq $\mathrm{NaCl}), \mathrm{c})$ PAH $\left(1 \mathrm{mg} \mathrm{mL}^{-1}, M_{\mathrm{n}}=56000 \mathrm{~g} \mathrm{~mol}^{-1}\right)$ and sodium citrate $\left(0.02 \mathrm{~mol} \mathrm{~L}^{-1}\right)$, d) PAH $\left(1 \mathrm{mg} \mathrm{mL}^{-1}, M_{\mathrm{n}}=15000 \mathrm{~g} \mathrm{~mol}^{-1}\right)$ and gold nanoparticles. The silicon wafers were slowly rotated to improve film homogeneity. Note that some samples show slight edge effects. 
experimental details for all examples described below are given in the Supporting Information.

For inorganic coatings, the general requirement is that the solubility limit of the sprayed compounds (i.e., of the complementary salts) is much larger than that of the resulting solid deposit. We present herein calcium fluoride $\left(\mathrm{CaF}_{2}\right)$ as a model case [Eq. (1)], but other inorganic deposits have also

$\mathrm{CaCl}_{2}(\mathrm{aq})+2 \mathrm{NaF}(\mathrm{aq}) \rightarrow \mathrm{CaF}_{2}($ solid film $)+2 \mathrm{NaCl}(\mathrm{aq})$

successfully been prepared: calcium hydrogen phosphate $\left(\mathrm{CaHPO}_{4}\right)$, calcium oxalate $\left(\mathrm{CaC}_{2} \mathrm{O}_{4}\right)$, Prussian blue $\left(\mathrm{Fe}_{4}\left[\mathrm{Fe}(\mathrm{CN})_{6}\right]_{3}\right)$, and silver chloride $(\mathrm{AgCl}$; see the Supporting Information). The preparation of some noble metal films ( $\mathrm{Au}$ and $\mathrm{Ag}$ ) and films of $\mathrm{CdS}$ and $\mathrm{ZnS}$ by similar methods was previously reported. ${ }^{[15-18]}$

For $\mathrm{CaF}_{2}$ layers, aqueous solutions of calcium chloride $\left(10^{-2} \mathrm{M}\right)$ and sodium fluoride $\left(2 \times 10^{-2} \mathrm{M}\right)$ were sprayed simultaneously in a 1:1 v/v ratio against a vertically oriented receiving surface. This procedure leads to solution concentrations higher than the solubility limit of $\mathrm{CaF}_{2}\left(2 \times 10^{-4} \mathrm{M}\right){ }^{[19]}$ After drying, the film thickness and morphology were determined by AFM and scanning electron microscopy (SEM) at different stages of growth, and the images show a good correlation between the thickness and the spraying time (Figure 2). We observed ongoing nucleation and growth of isolated monocrystalline particles, which eventually leads to the formation of a dense layer of $\mathrm{CaF}_{2}$. The polycrystalline nature of the resulting deposit was confirmed by transmission electron diffraction (Figure $2 \mathrm{a}$ ). The growth then continues perpendicularly to the substrate and the film thickness increases steadily with spraying time.
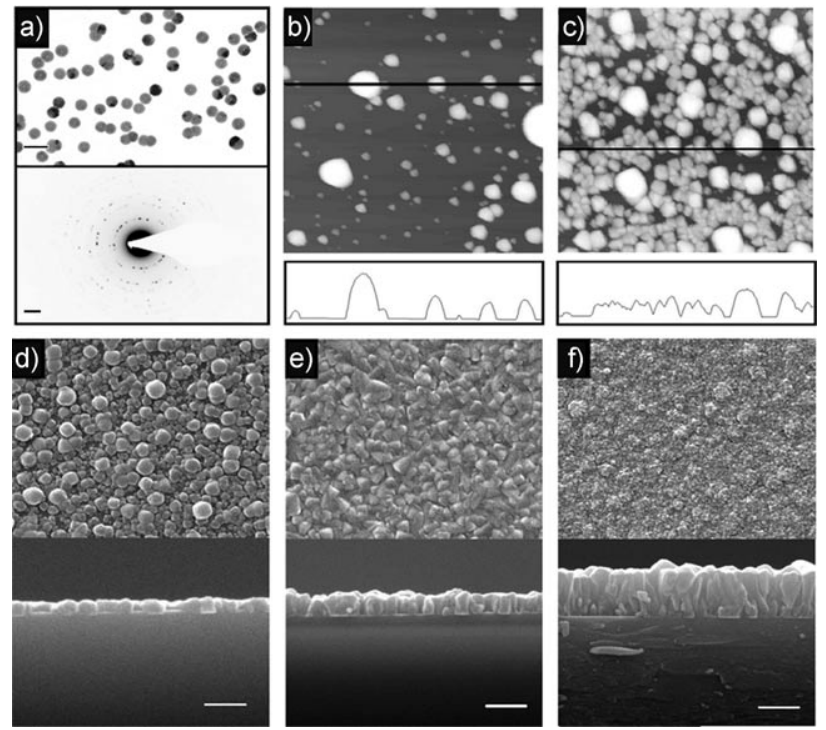

Figure 2. Micrographs of $\mathrm{CaF}_{2}$ coatings obtained by spraying for: a) $1 \mathrm{~s}$ on a Formvar support, analyzed by TEM, scale bar $0.5 \mu \mathrm{m}$ (top) and electron diffraction, scale bar $0.2 \mathrm{~nm}^{-1}$ (bottom); b) $10 \mathrm{~s}$ and c) $40 \mathrm{~s}$ on a silicon wafer, analyzed by AFM topography (top) and line profiles (bottom). The scan areas for both b) and c) are $5 \mu \mathrm{m} \times 5 \mu \mathrm{m}$, the $z$-axis scale is $400 \mathrm{~nm}$; d) $1 \mathrm{~min}$, e) $5 \mathrm{~min}$, and f) $10 \mathrm{~min}$ on a glass substrate, analyzed by SEM, top views (top) and cross-section images (bottom). The scale bars in (d) and (f) are $2 \mu \mathrm{m}$.
As in the case of inorganic layers, the general requirement for polymer-based SSCIS films is a rapid reaction between the components, which leads to complex formation. The strength and versatility of electrostatic complex formation [Eq. (2)]

polyanion $(\mathrm{aq})+$ polycation $(\mathrm{aq}) \rightarrow$

polyanion - polycation complex (solid film) + counterions $(\mathrm{aq})$

renders it particularly well suited for SSCIS. In addition, as in the case of electrostatic LbL deposition, the polyanionic and polycationic nature of the compounds leads to a wide choice of different materials. ${ }^{[20,21]}$

Several pairs of strong and weak polyelectrolytes, for which classic LbL assembly has already been reported, were investigated for SSCIS film formation. Such film formation by simultaneous spraying has only been reported once for a pair of weak polyelectrolytes, namely poly(glutamic acid) (PGA) and poly(allylamine hydrochloride) (PAH). ${ }^{[22]}$ All investigated systems, that is, dextran sulfate/poly(L-lysine) (PLL), poly(styrene sulfonate) (PSS)/poly(allylamine hydrochloride) (PAH), poly(dimethyl diallyl ammonium chloride) (PDADMAC)/poly(acrylic acid) (PAA), poly (ethylene imine) (PEI)/ PAA, and PAH/PAA, show a linear film growth as a function of spraying time (Figure 3; the term spraying time represents the cumulated spraying time). An interruption of the deposition does not influence the growth rate of the films (to within experimental error). The same film thicknesses are obtained, regardless of whether the film is grown in a single step or in multiple steps while the overall spraying time is kept constant, and even if the film is dried after each step. This behavior is observed for both polymer-based and inorganic coatings and demonstrates that the SSCIS process is very robust.

Another interaction that is sufficiently strong for the preparation of SSCIS films is hydrogen bonding, as illustrated

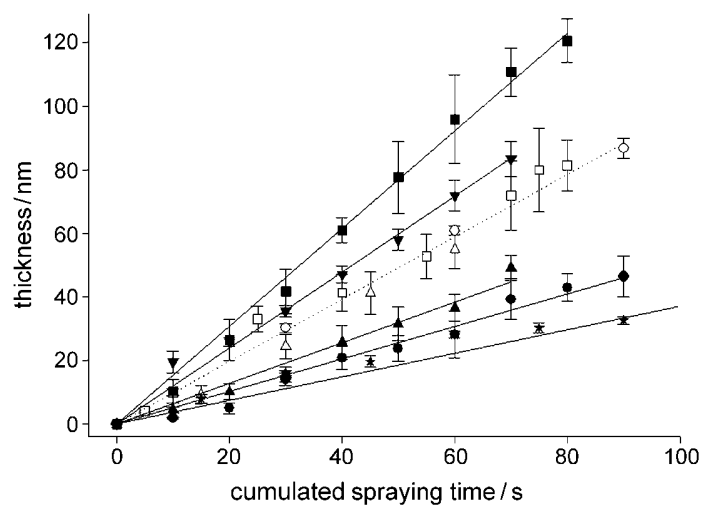

Figure 3. Ellipsometric film thickness as a function of the spraying time for different polymeric systems; $\mathbf{m}$ : dextran sulfate $\left(0.5 \mathrm{mg} \mathrm{mL}^{-1}\right)$ and PLL $\left(0.5 \mathrm{mg} \mathrm{mL}^{-1}\right)$ at $\mathrm{pH} 7.5 ; \mathbf{\nabla}$ : PEO $\left(0.5 \mathrm{mg} \mathrm{mL}^{-1}\right)$ and PAA $\left(0.5 \mathrm{mg} \mathrm{mL}^{-1}\right)$ at $\mathrm{pH} 2 ; \circ, \square, \triangle$ : PSS $\left(0.5 \mathrm{mg} \mathrm{mL}^{-1}\right)$ and $\mathrm{PAH}$ $\left(0.5 \mathrm{mg} \mathrm{mL}^{-1}\right)$ at $\mathrm{pH} 7.5$ with $5 \mathrm{~s}, 15 \mathrm{~s}$, and $30 \mathrm{~s}$ spraying intervals respectively; $\Delta$ : PDADMAC $\left(0.5 \mathrm{mg} \mathrm{mL}^{-1}\right)$ and PAA $\left(0.5 \mathrm{mg} \mathrm{mL}^{-1}\right)$ at $\mathrm{pH} 7.5$; •: PEI $\left(0.5 \mathrm{mg} \mathrm{mL}^{-1}\right)$ and PAA $\left(0.5 \mathrm{mg} \mathrm{mL}^{-1}\right)$ at $\mathrm{pH} 7.5 ; *$ : $\mathrm{PAH}\left(0.5 \mathrm{mg} \mathrm{mL}^{-1}\right)$ and PAA $\left(0.5 \mathrm{mg} \mathrm{mL}^{-1}\right)$ at $\mathrm{pH} 7.5$. The error bars represent the standard deviation. 
by the regular growth of the PAA/poly(ethylene oxide) (PEO) system (Figure 3). In solution, this system shows strong complexation below a $\mathrm{pH}$ value of approximately 3.5 . SSCIS films are built up by simultaneous spraying at $\mathrm{pH} 2$, and can easily be dissolved at $\mathrm{pH}$ values above 5 , similar to PAA/PEO LbL films. ${ }^{[23]}$

One interesting aspect of polyanion/polycation complex formation is its dependence on the relative degrees of polymerization of both polyelectrolytes; these values are typically highest when the lengths of both compounds match. ${ }^{[21]}$ However, simultaneous spraying of a polyelectrolyte with an oppositely multicharged small oligoion can unexpectedly lead to film formation. For such systems, we present $\mathrm{PAH}$ and sodium citrate as a model case, as these compounds do not allow conventional LbL deposition. Films of other components $\left(\mathrm{PAH} / \mathrm{K}_{3}\left[\mathrm{Fe}(\mathrm{CN})_{6}\right]\right.$, PAH/sodium oxalate, $\mathrm{PAH} /$ phytic acid sodium salt, $\mathrm{PAA} /$ spermine, and $\mathrm{PAH} /$ sulfated $\alpha$-cyclodextrin sodium salt) were also successfully prepared by SSCIS (see the Supporting Information). In all these cases, the film growth is regular with respect to the spraying time. In the case of PAH and sodium citrate, the film deposition could be followed by AFM, and the mechanism for film formation was derived. At the initial stages of the buildup, the layer is rather inhomogeneous and is constituted of isolated droplet-like objects (Figure $4 \mathrm{a}$ ), which grow in size and also increase in number. With further spraying, these structures coalesce upon lateral contact, thus forming a film with holes (Figure 4b) and finally a continuous and very smooth coating (Figure 4c and Figure 1c). A similar development of morphologies as a function of spraying time was also

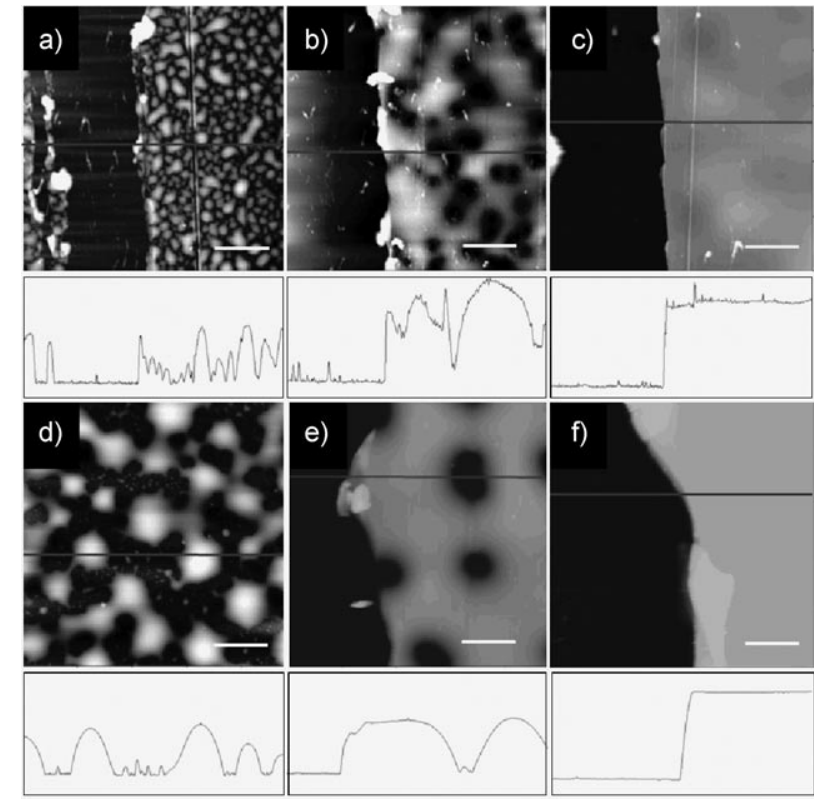

Figure 4. AFM topography (top) and line profiles (bottom) of SSCIS films on silicon wafers of: a-c) PAH/citrate after spraying times of $30 \mathrm{~s}, 75 \mathrm{~s}$, and $120 \mathrm{~s}$ of spraying time, respectively; d-f) PDADMAC/ PAA after spraying times of $70 \mathrm{~s}, 120 \mathrm{~s}$, and $180 \mathrm{~s}$, respectively. Scan areas are $12 \mu \mathrm{m} \times 12 \mu \mathrm{m}$ and the scale bars are $2.5 \mu \mathrm{m}$. For a proper determination of height profiles, that is, the film thickness, the films were scratched. For line profiles, the $\gamma$-axis scales from 0 to $120 \mathrm{~nm}$ $(\mathrm{a}-\mathrm{c})$ and from 0 to $400 \mathrm{~nm}(\mathrm{~d}-\mathrm{f})$. observed for polyanion/polycation systems such as PDADMAC/PAA (Figure 4d-f).

SSCIS films of PAH and sodium citrate rapidly dissolve when immersed in aqueous solutions of $\mathrm{NaCl}$ at ionic strengths above $0.15 \mathrm{M}$, thus offering possibilities for use as bioresponsive materials or triggered release applications. The rapid degradation of such films can easily be prevented and controlled by cross-linking, for example by heating at $130^{\circ} \mathrm{C}$ for 18 hours in an oven or by heating with a heat gun for 2-3 minutes. This process leads to partial thermal cross-linking by formation of amide bonds through reaction of the carboxylic acid groups of citrate with the amino groups of $\mathrm{PAH}$; this behavior is similar to a case described for LbL films. ${ }^{[2]}$

The SSCIS method also allows for in situ chemical crosslinking of films by adding reactive components to the spraying solutions. In the case of $\mathrm{PAH} /$ citrate films, the addition of glutaraldehyde to the citrate solution leads to the formation of a covalent network through Schiff base formation. ${ }^{[25]}$ Such coatings do not dissolve in brine over a long period of time. Interestingly, the simultaneous spraying of PAH and glutaraldehyde in the absence of citrate ions did not lead to the formation of any films. Different functionalities in addition to chemical reactivity can also be incorporated into SSCIS films by spraying multicomponent solutions simultaneously. For example, gold nanoparticles (1st component) stabilized with citrate (2nd component), which are sprayed simultaneously with PAH (3rd component) result in very smooth films (Figure 1d) that display regular growth like all other systems presented above. In addition, the presence of gold nanoparticles offers the advantage of monitoring film growth by changes in the plasmon band (see the Supporting Information).

The simplicity and broad applicability of the SSCIS method is proved by the different systems described here, even without detailed studies of the parameters and variables involved in spraying technologies. The growth rates and coating morphologies not only depend on spraying time, but are expected to also be a function of solution concentration, nozzle type, spraying rate, spraying distance, and other factors. SSCIS is very flexible, yet robust, and the method can be quickly adapted to different requirements through further optimization of such parameters.

While LbL deposition methods have received considerable attention because of their widespread potential applications (e.g., biomaterial coatings, ${ }^{[26]}$ fuel cells, ${ }^{[27,28]}$ and anticorrosion protection ${ }^{[29]}$, not all of them require a stratified structure of the film at the nanometer scale. In such cases, simultaneous spray coating offers a much faster option, which is also applicable to larger surfaces. The SSCIS spray technology with two nozzles described here can be extended to multinozzle systems for the preparation of coatings with gradients along the layer normal, including sandwich-like films made from different materials through multisequence spraying.

Received: May 5, 2010

Published online: November 23, 2010 
Keywords: coatings - functional materials - nanotechnology · surface chemistry $\cdot$ thin films

[1] B. D. Ratner, A. S. Hoffman, Biomaterials Science: An Introduction to Materials in Medicine, 2nd ed., Elsevier Academic, San Diego, CA, 2004.

[2] P. W. Baumeister, Optical Coating Technology, SPIE, Bellingham, WA, 2004.

[3] F. C. Krebs, Sol. Energy Mater. Sol. Cells 2009, 93, 394.

[4] Z. Ahmad, Principles of Corrosion Engineering and Corrosion Control, Elsevier, Oxford, UK, 2006.

[5] K. L. Choy, Prog. Mater. Sci. 2003, 48, 57.

[6] J. E. Mahan, Physical Vapor Deposition of Thin Films, Wiley, New York, 2000

[7] L. C. Klein, Sol-Gel Technology for Thin Films, Fibers, Preforms, Electronics, and Specialty Shapes, Noyes Publications, Park Ridge, NJ, 1988.

[8] I. Ichinose, H. Senzu, T. Kunitake, Chem. Mater. 1997, 9, 1296.

[9] P. S. Patil, Mater. Chem. Phys. 1999, 59, 185.

[10] G. Decher, Science 1997, 277, 1232.

[11] L. Winterton, J. Vogt, J. Lally, F. Stockinger (Novartis AG), World Patent WO 9935520, 1999.

[12] J. B. Schlenoff, S. T. Dubas, T. Farhat, Langmuir 2000, 16, 9968.

[13] A. Izquierdo, S. S. Ono, J.-C. Voegel, P. Schaaf, G. Decher, Langmuir 2005, 21, 7558.

[14] K. C. Krogman, J. L. Lowery, N. S. Zacharia, G. C. Rutledge, P. T. Hammond, Nat. Mater. 2009, 8, 512.
[15] D. J. Levy (Lockheed Aircraft Corporation), US Patent No. US 3515571,1970

[16] D. O'Brian, J. Vogler, J. M. Landry, G. S. Jakubowski, US Patent No. US 6168 825, 2001.

[17] A. Sakurai, J. Togasaki (Advance Company Ltd, Ohra Sangyo Co. Ltd), European Patent No. EP 1557 483, 2005.

[18] K. Kalberlah, Z. Mollah, German Patent No. DE 102004020 879, 2005.

[19] E. C. Weast, Handbook of Chemistry and Physics, 57th ed., CRC Press, Cleveland, OH, 1976-1977.

[20] B. Philipp, H. Dautzenberg, K. J. Linow, J. Koetz, W. Dawydoff, Prog. Polym. Sci. 1989, 14, 91.

[21] A. F. Thünemann, M. Müller, H. Dautzenberg, J. F. O. Joanny, H. Löwen, Adv. Polym. Sci. 2004, 166, 113.

[22] C. Porcel, A. Izquierdo, V. Ball, G. Decher, J.-C. Voegel, P. Schaaf, Langmuir 2005, 21, 800.

[23] S. A. Sukhishvili, S. Granick, Macromolecules 2002, 35, 301.

[24] S. Y. Yang, M. F. Rubner, J. Am. Chem. Soc. 2002, 124, 2100.

[25] G. T. Hermanson, Bioconjugate techniques, Academic Press, San Diego, CA, 1996

[26] Z. Y. Tang, Y. Wang, P. Podsiadlo, N. A. Kotov, Adv. Mater. 2006, $18,3203$.

[27] J. L. Lutkenhaus, P. T. Hammond, Soft Matter 2007, 3, 804.

[28] A. D. Taylor, M. Michel, R. C. Sekol, J. M. Kizuka, N. A. Kotov, L. T. Thompson, Adv. Funct. Mater. 2008, 18, 3003.

[29] D. Fix, D. V. Andreeva, Y. M. Lvov, D. G. Shchukin, H. Möhwald, Adv. Funct. Mater. 2009, 19, 1720. 